\title{
Stop killing healthcare workers in South Sudan
}

\author{
Dr Edward Eremugo Kenyi \\ Editor-in-Chief \\ South Sudan Medical Journal
}

As South Sudan marked the 10th anniversary of independence from Sudan on 9 July 2021, the healthcare professionals were mourning the brutal murder of a medical doctor at his duty station. Dr Louis Edward Saleh, who was working at the Ganyiel PHCC in Panyijiar County of Unity State for the International Rescue Committee (IRC), was killed in cold blood within the health facility on 21 May 2021.

The government condemned the killing of Dr Louis. ${ }^{[1]}$ The UN Office for the Coordination of Humanitarian Affairs (OCHA) Humanitarian Coordinator in South Sudan ${ }^{[2]}$, and the South Sudan Doctors' Union (SSDU) also condemned the killing and called for investigations and justice. ${ }^{[3]}$ However, to date, the perpetrators of this heinous crime have not been apprehended.

Shortly afterward, the healthcare fraternity was shocked again to learn that Dr Dominic Pitia, who worked for Care International as the Emergency Health Manager in Akobo, Jonglei State, was found dead in his room on 27 July 2021, in a similarly unclear circumstance. This killing drew widespread condemnation from local and international organizations. Another statement from the SSDU on 28 July 2021 noted that this "killing or mistreatment of health workers would affect the availability of health professionals to provide health services to communities in remote areas where there is no proper law enforcement and access to justice." ${ }^{\text {"[4] }}$

Other humanitarian workers have continued to be killed in different parts of the country while delivering services to needy communities ${ }^{[5,6]}$ According to OCHA, a total of 126 humanitarian workers, mostly South Sudanese, have lost their lives while providing critical assistance to people across the country since the conflict broke out in late 2013.

The targeting of healthcare workers in South Sudan must stop. Healthcare and humanitarian workers are there to serve our communities. They do not distinguish patients by their race, ethnicity, culture, language, or geographical location. They are there to save lives, and they should be protected, a responsibility that falls squarely on the Government, be it local or state.

We call on the Government to provide security for healthcare and humanitarian workers as they deliver life-saving care to the needy and suffering people of South Sudan. It is time for us to stand together with all health workers, call for an end to these heinous attacks, and urgently demand the arrests of the criminals.

The time for action is now.

\section{References}

1. Government Statement on the Heinous and Inhumane Murder of Dr. Louis Edward Saleh Ufew, in Ganyliel, Panyijar County, Unity State. Northern Corridor Morning Post. 14 June 2021.

2. UN OCHA, UN condemns killing of one aid worker and attack against humanitarian convoy in Unity State, Press release. 23 May 2021.

3. South Sudan Doctors' Union, Condemnation of the Killing of two medical professionals and call for action. Press Release. 23 May 2021.

4. South Sudan Doctors' Union, Statement on the death of Dr Dominic Pitia, Press Release. 28 July 2021.

5. USAID, Condemning Violence Against Humanitarian Workers in South Sudan, Statement by Administrator Samantha Power. Press Release. 28 May 2021.

6. UN OCHA, Humanitarian Coordinator a.i. in South Sudan condemns attack on aid workers and assets in Tonj North, Warrap. Press Release. 14 July 2021. 